\title{
Impacts of climate change on the water regime of the Inn River basin - extracting adaptation-relevant information from climate model ensembles and impact modelling
}

\author{
J. Korck ${ }^{1}$, J. Danneberg ${ }^{1}$, and W. Willems ${ }^{2}$ \\ ${ }^{1}$ Bayerisches Landesamt für Umwelt, Hof, Germany \\ ${ }^{2}$ Ingenieurhydrologie, Angewandte Wasserwirtschaft und Geoinformatik, Ottobrunn, Germany \\ Correspondence to: J. Korck (jane.korck@lfu.bayern.de)
}

Received: 31 January 2012 - Revised: 2 August 2012 - Accepted: 18 October 2012 - Published: 20 December 2012

\begin{abstract}
The Inn River basin is a highly relevant study region in terms of potential hydrological impacts of climate change and cross boundary water management tasks in the Alpine Space. Regional analyses in this catchment were performed within the EU co-funded project AdaptAlp. Objective of the study was to gain scientifically based knowledge about impacts of climate change on the water balance and runoff regime for the Inn River basin, this being fundamental for the derivation of adaptation measures.

An ensemble of regional climate projections is formed by combinations of global and regional climate models on the basis of both statistical and bias-corrected dynamical downscaling procedures. Several available reference climate datasets for the study region are taken into account. As impact model, the process-oriented hydrological model WaSiM-ETH is set up.

As expected, regional climate projections indicate temperature increases for the future in the study area. Projections of precipitation change are less homogenous, especially regarding winter months, though most indicate a decrease in the summer. Hydrological simulation results point towards climate induced changes in the water regime of the study region. The analysis of hydrological projections at both ends of the ensemble bandwidth is a source of adaptation relevant information regarding low-flow and high-flow conditions. According to a "drought-prone scenario", mean monthly low flow could decrease up to $-40 \%$ in the time frame of 20712100. A "high-flow-increase-scenario" points towards an increase in mean monthly high flow in the order of $+50 \%$ in the winter, whilst showing a decrease in autumn.
\end{abstract}

\section{Introduction}

The hydrology of Alpine catchments plays a crucial role for water availability in central Europe. At the same time, the region is sensitive to climate change and has experienced a temperature increase of $1.2^{\circ} \mathrm{C}$ in the past century. This is more than twice as high as the average increase in the Northern Hemisphere. Alpine precipitation changes are highly variable with increasing and decreasing trends depending on region and season (Auer et al., 2007, spatial extent of the analysed region: $\left.4-19^{\circ} \mathrm{E}, 43-49^{\circ} \mathrm{N}\right)$. The Inn River basin is a highly relevant study region in terms of potential impacts of climate change on hydrological processes and cross boundary water management tasks. Regional analyses for the Inn River basin were performed within the EU co-funded project AdaptAlp (2008-2011). The objective of the study was to gain scientifically based knowledge about the impacts of climate change on the water regime of the Inn River and to derive information on which to base adaptation measures in the context of multiple uncertainties in the applied methods.

\section{Area of interest}

The Inn and its tributaries span a catchment of more than $26000 \mathrm{~km}^{2}$ in four countries (Fig. 1). The water regime of the Inn is greatly influenced by the complex terrain and heterogeneous climate of the southern part of the basin which has typically alpine characteristics (e.g. altitudes up to $4000 \mathrm{~m}$ a.s.l. and steep gradients, high annual precipitation amounts and low mean temperatures in the summit regions). 


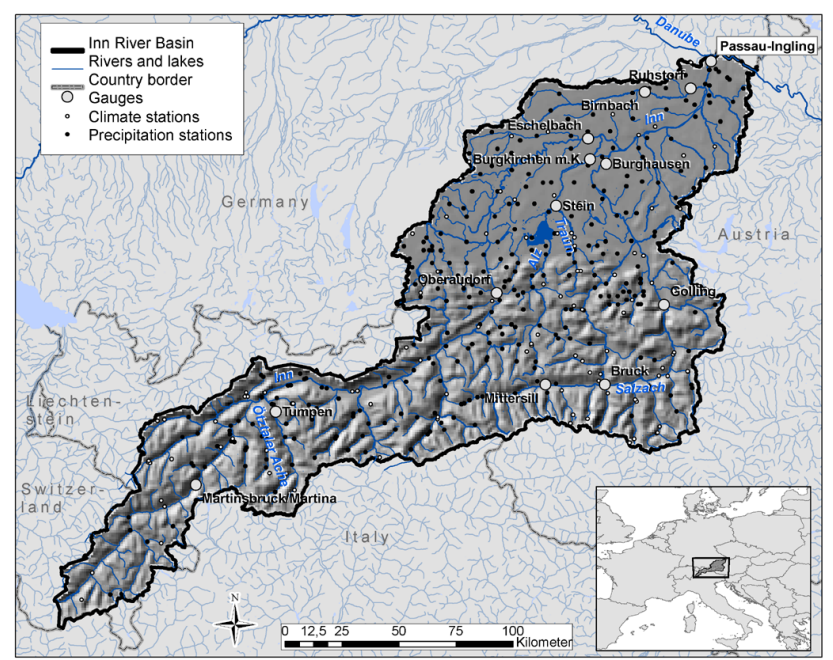

Fig. 1. Inn River basin, location of climate and precipitation stations and selected gauges.

This particularly affects seasonal and spatial precipitation distribution and snow melt dynamics. The average temperature is $6.3^{\circ} \mathrm{C}(1971-2000$, annual mean of 104 climate stations in altitudes of 300-3300 m a.s.l.). The average annual precipitation for the period 1971-2000, according to a long term water balance simulation of the study region performed with the hydrological model WaSiM-ETH, is $1425 \mathrm{~mm}$ (see Sect. 3.2 for details on the precipitation interpolation).

Half of the annual runoff of the Inn River is produced from May to August (Fig. 2). Low flows occur more often in the dry and cold winter months, and the most extreme flood events result from extreme precipitation in summer during so called "Vb cyclones" (e.g. Gattermayr and Steck, 2006; Bayerisches Landesamt für Wasserwirtschaft, 2002; LfU, 2007). In Bard et al. (2011), some changes in the water regime of the Inn River basin have already been observed, like an earlier start of the snowmelt season and an increasing annual minimum flow. Though human activities, especially water management and land use, have also affected the water regime of the Inn over time, the careful selection of data for the trend analyses point to climate induced changes (KLIWA, 2002; Bard et al., 2011).

\section{Methodological approach}

\subsection{Impact model chain}

In order to analyse the possible local impacts of global and regional climate change, a so-called "climate impact model chain", or in short "model chain", is applied. As shown in Fig. 3, the model chain starts with a global greenhouse gas emissions scenario which provides the basis for global climate simulations using Global Climate Models (GCMs). The regional output of the GCMs provides the input for Regional

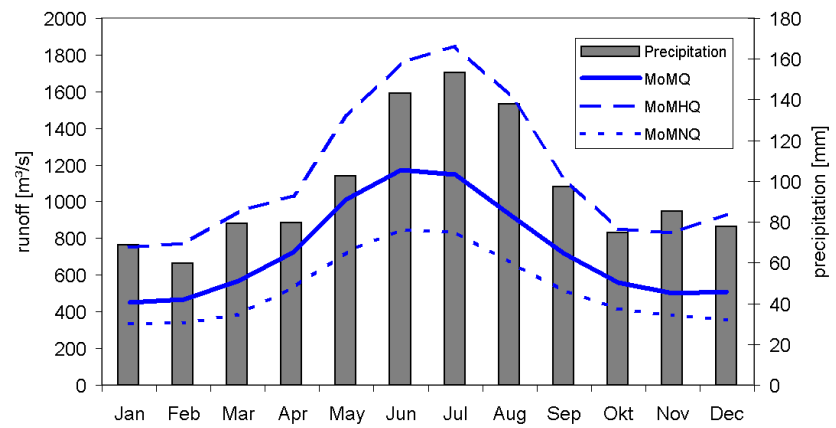

Fig. 2. Observed mean monthly discharge (MoMQ), mean monthly high flow (MoMHQ) and mean monthly low flow (MoMNQ) at the exit gauge Passau-Ingling and average monthly precipitation for the Inn River basin (period 1971-2000).

Climate Models (RCMs), that can be either statistical or dynamic (physically based) models for downscaling numerous climate variables to a regionally, and in some cases locally, relevant scale. For the Alpine Space, and therefore also for large parts of the Inn River basin, the question of model resolution is highly relevant. Most GCMs still have resolutions of more than $150 \times 150 \mathrm{~km}^{2}$, so one grid box covers an area about the size of the study area.

Against this backdrop, the role of the RCMs, which are run at resolutions of $25 \times 25 \mathrm{~km}^{2}$ and below, is extremely important. They constitute the first point in the model chain where it becomes possible to represent some of the orographic detail that characterises the highly complex terrain in the Alpine Space. However, for the analysis of locally relevant questions using, for example, hydrological models, an even higher spatial resolution can prove necessary.

All dynamic RCMs and their driving GCMs display not only a general model uncertainty, meaning a random deviation from observed climate values in a reference time period, but also a certain model bias, meaning a systematic over- or underestimation of important climate variables. This is due to still unknown physical processes in the atmosphere-ocean interaction, and to the necessary simplification of processes in the models. In a study by Krahe et al. (2009), the model bias of regional dynamic models in a comparable study area, the catchment of the Alpine Rhine, was shown to cause a systematic overestimation of monthly precipitation amounts as well as seasonal under- and overestimations of the air temperatures.

The findings of Krahe et al. (2009) and other authors have led to the conclusion that the data from regional dynamical projections cannot be used directly in impact models (Fowler et al., 2007; Graham et al., 2007; Mudelsee et al., 2010). Therefore, the next step in the model chain for all dynamic RCMs is further downscaling in combination with bias-correction. The procedures are based on statistical correction functions which have been shown to reduce the bias with respect to the reference data in the past and are therefore 


\begin{tabular}{|c|c|c|c|c|}
\hline $\begin{array}{l}\text { Emission } \\
\text { scenario }\end{array}$ & $\rightarrow \begin{array}{c}\text { Global } \\
\text { Climate } \\
\text { Model (GCM) }\end{array}$ & $\rightarrow \begin{array}{c}\text { Regional Statistical } \\
\text { Climate } \\
\text { Model (RCM) Dynamical }\end{array}$ & $\overrightarrow{\text { Bias-Correction }}$ & $\begin{array}{c}\text { Water } \\
\text { balance } \\
\text { model }\end{array}$ \\
\hline
\end{tabular}

Fig. 3. Schematic diagram representing the elements of the climate impact modelling chain.

applied to the climate projection data in the future. This step is based on the assumption that the reference data represents the true past climate and that the bias has been quantified correctly and will remain the same in the future. In this context it is important to note that the downscaling procedures applied in statistical RCMs are based on entirely different methods. Because of the underlying methodology, bias-correction is not applied to statistical RCMs.

The final step in the model chain is impact modelling. In this study, hydrological simulations were performed using the calibrated model system WaSiM-ETH (version 8.06.02) at $1 \mathrm{~km}^{2}$ resolution and daily time step for the Inn River basin. The grid based hydrological model describes hydrological processes of transport, storage and phase transition on the basis of simplified physical equations on a catchment scale (Schulla, 1997; Schulla and Jasper, 1998). The soil model takes into account soil water dynamics by solving the Richards Equation for the movement of fluid in a porose medium (Schulla and Jasper, 2007). Station-based input climate data are regionalised using variable-specific interpolation schemes, for example an extended Inverse Distance Weighting (IDW) method that has been proven to describe spatial hydrometeorological characteristics in the catchment adequately (LfU, 2010).

The implementation of the model chain resulted in different combinations of global and regional climate models, downscaling procedures and impact modelling. All the results were analysed in terms of plausibility and climate change signal. In addition, selected plausible projections were analysed more closely with regard to adaptation relevant information.

\subsection{Reference data}

The choice of a reference climate dataset plays a crucial role within the climate impact modelling chain. The most important climate variable for water balance modelling is precipitation, but this parameter in particular is connected with high uncertainties not only due to the measurement procedures, but also to the highly heterogeneous spatial and seasonal distribution of precipitation in an alpine environment. The distribution of the 415 available precipitation stations, located in altitudes between 300 and $3300 \mathrm{~m}$ a.s.l., can be seen in Fig. 1. The interpolation of the point measurements onto grid cells of varying size can be performed with different methods (Weilguni, 2006). It has to be kept in mind that the "real" precipitation and climate in the study regions remains unknown. One measure for the validation of the representation of precipitation within the model chain is the comparison of simulated and measured runoff after using the interpolated precipitation data in a water balance model. Water balance simulations with the hydrological model WaSiM-ETH revealed that a combination of IDW and elevation regression generated best results for most sub catchments in the Inn River basin (LfU, 2010). Other less altitude dependent regionalisation methods tended to result in lower precipitation sums and discharge deficits in the most mountainous parts of the basin.

In addition, the "WaSiM" dataset, which constitutes the climate data that is regionalised in the hydrological model, was compared to other selected climate datasets for the study region. Several climate datasets are available for the Alpine Space, all applying different regionalisation techniques for the interpolation of station data. A description of the datasets and regionalisation methods can be found in LfU (2011). The comparison of the datasets was based on criteria like the mean annual and monthly total precipitation in the whole Inn basin and several subcatchments, the mean annual and monthly temperatures, and also variables that characterise extreme precipitation. The comparison showed that mean annual values as well as the extreme values differ significantly, and the differences increase with rising mean altitude of the subcatchments. It was concluded that datasets with strong altitude dependence in the underlying interpolation approach, like the WaSiM dataset, are better suited for the strong relief of the study region.

To ensure consistency in the model chain, the dataset "WaSiM" was used (a) as a reference for the assessment of the performance of regional climate models in the study area, (b) as the basis for the calibration of the hydrological model and (c) as the basis for the bias-correction.

\subsection{Climate models}

The ensemble of regional climate projections included in this study is based on the moderate IPCC emissions scenario A1B (greenhouse gas emissions scenario of the Intergovernmental Panel on Climate Change (IPCC) Special Report on Emissions Scenarios; Nakicenovic et al., 2000). Several combinations of global and regional climate models and both statistical downscaling methods and dynamical downscaling followed by bias-correction procedures were included (Table 1). Initially, a total of 14 regional climate projections were included in the study (plus two further datasets REM_uba and REM_ubv, which are both variations of the REMO UBA regional climate model; UBA, 2006). WETTREG (Spekat et al., 2007) is a statistical downscaling approach developed and widely used in Germany (e.g. KLIWA, 2006), which is considered more reliable for the near future than the distant future. The four "GLOWA" projections, which were developed and applied in the GLOWA Danube project (2010), are simulation results of a "climate generator" using trends based on other available climate projections. The dynamic regional climate models originate from the EU FP6 project 
Table 1. Model chain combinations and abbreviations; analysed time periods: reference 1971-2000, "near future" 2021-2050, "distant future" 2071-2100.

\begin{tabular}{|c|c|c|c|c|}
\hline $\mathrm{RCM}$ & GCM & $\begin{array}{l}\text { Abbreviations } \\
\text { (used in graphs) }\end{array}$ & Model resolution & $\begin{array}{l}\text { Used in } \\
\text { impact } \\
\text { model }\end{array}$ \\
\hline \multicolumn{5}{|l|}{ Climate projections from statistical downscaling } \\
\hline WETTREG 2010 & ECHAM5 r1 & WET10_eh & Stations, downscaled to grid $1 \mathrm{~km}$ & Yes \\
\hline WETTREG 2009 & ECHAM5 r1 & WET09_eh & Stations, downscaled to grid $1 \mathrm{~km}$ & No \\
\hline WETTREG 2009 & HadGEM2-AO & WET09_hd & Stations, downscaled to grid $1 \mathrm{~km}$ & Yes \\
\hline WETTREG 2009 & CNRMCM3 & WET09_cn & Stations, downscaled to grid $1 \mathrm{~km}$ & No \\
\hline GLOWA Fortschreibung & (Climate trend based on station data) & GLO_frt & Grid, $1 \mathrm{~km}$ & Yes \\
\hline GLOWA Trend IPCC & (Climate trend based on $21 \mathrm{GMs}$ ) & GLO_ipc & Grid, 1 km & No \\
\hline GLOWA Trend REMO & (Climate trend based on ECHAM5 r1-REMO) & GLO_rem & Grid, 1 km & Yes \\
\hline GLOWA Trend MM5 & (Climate trend based on ECHAM5 r1-MM5) & GLO_mm5 & Grid, $1 \mathrm{~km}$ & No \\
\hline \multicolumn{5}{|c|}{ Dynamic regional climate models, bias corrected } \\
\hline REMO UBA & ECHAM5 r1 & REM_uba_b & Grid, downscaled from $10 \mathrm{~km}$ to $5 \mathrm{~km}$ & Yes \\
\hline REMO BFG & ECHAM5 r2 & REM_bfg_b & Grid, downscaled from $10 \mathrm{~km}$ to $5 \mathrm{~km}$ & Yes \\
\hline REMO ENSEMBLES & ECHAM5 r3 & REM_ens_b & Grid, downscaled from $10 \mathrm{~km}$ to $5 \mathrm{~km}$ & Yes \\
\hline CCLM ENSEMBLES & HadCM3 & CLM_hd_b & Grid, downscaled from $25 \mathrm{~km}$ to $5 \mathrm{~km}$ & Yes \\
\hline CLM CONSORTIAL EH5r1 & ECHAM5 r1 & CLM_eh_b & Grid, downscaled from $18 \mathrm{~km}$ to $5 \mathrm{~km}$ & Yes \\
\hline CLM CONSORTIAL EH5r2 & ECHAM5/ MPIOM & CLM_eh2_b & Grid, downscaled from $18 \mathrm{~km}$ to $5 \mathrm{~km}$ & Yes \\
\hline \multicolumn{5}{|c|}{ Other versions of REMO UBA for comparison regarding precipitation } \\
\hline REMO UBA without bias-correction & ECHAM5 r1 & REM_uba & Grid, $10 \mathrm{~km}$ & \\
\hline REMO UBA with precipitation correction & ECHAM5 r1 & REM_ubv & Grid, $10 \mathrm{~km}$ & \\
\hline
\end{tabular}

ENSEMBLES (Van der Linden and Mitchell, 2009) or from climate research institutes in Germany (Jacob, 2006; Hollweg et al., 2008; Lautenschlager et al., 2009; Jacob et al., 2009; Keuler et al., 2009a, b, c). The RCMs have different spatial resolutions (see Table 1 for details). Regarding temporal resolution, all climate parameters are available in daily time steps. The reference time period is 1971-2000, the analysed future time periods are 2021-2050 ("near future") and 2071-2100 ("distant future").

Bias-correction for the climate variables precipitation, temperature, and sunshine duration was performed by the German Federal Institute of Hydrology (BfG) within the EUproject AdaptAlp, using quantile-quantile mapping for precipitation and linear scaling for temperature and sunshine duration. For details on the models and the bias-correction procedures, please refer to the AdaptAlp technical report (LfU, 2011; Krahe et al., 2012).

Within the scope of this study it was not possible to perform hydrological simulations for all the available RCMs. A reduced number of RCM runs was selected according to the following criteria: (1) plausibility of the individual RCM runs: as described in Sect. 4.1, the output of the climate model runs was compared with reference data for the past, to assess the plausibility of the projections. (2) Representation of the full range of the climate signals detected in the original group of 14: to achieve this, the simulation runs were compared for the near and distant future for various variables and measures (LfU, 2011). (3) Representation of the different methodological approaches described above.
As a result of these considerations, $10 \mathrm{RCMs}$ were selected as input for hydrological modelling: four statistical and six bias-corrected dynamic RCM runs (Table 1).

\section{Results}

\subsection{Validation}

In a first validation step, the plausibility of the climate projections in the reference period (1971-2000) was analysed by comparing the climate model output with reference data. The results are shown in detail in LfU (2011). All models performed well for the long-term means of climate variables, e.g. mean annual precipitation is simulated with differences of less than $\pm 10 \%$ compared to the reference. This was to be expected, as both statistical downscaling methods and biascorrection methods are based on observed data. On the other hand, all models showed weaknesses in reproducing measures of extreme and rare events, e.g. the measure of the number of days with precipitation sums of more than $20 \mathrm{~mm}$. For the winter months (DJF), for example, the projections show differences in the order of $\pm 30 \%$ compared to the reference. The observational dataset "WaSiM-ETH", used as a reference for validation, also showed deficits for this type of measure (LfU, 2011). Therefore, reproducing extreme precipitation characteristics is not only a weakness in regional climate modelling, but also poses a problem in observational datasets. Consequently, the analysis of climate projections for the future with regard to these statistics remains a complex problem. 
In a second step, the plausibility of the model chain was validated from the "impact end" for the 10 projections used in hydrological modelling, by assessing the performance of the different model chain realisations in reproducing runoff indicators for the past at several gauges in the catchment. If the combination of global model, regional model, in some cases bias-correction, and impact model is able to reproduce certain measures that describe observed hydrological conditions in the past, this is taken as proof of the reliability of the whole model chain for these specific measures, also for the future. Validation was satisfactory for mean monthly runoff (MoMQ), mean monthly high flow (MoMHQ), and mean monthly low flow (MoMNQ), with deviations from the reference of, in most cases, less than $\pm 10 \%$ (LfU, 2011).

Regarding low flow extremes for the Inn River basin, the discharge for low-flow events occurring statistically every $50 \mathrm{yr}$ (NQ50) was analysed. The measure was calculated using extreme value analyses based on measured discharge and discharge simulated using the model chain realisations. The comparison showed differences of less than $\pm 20 \%$ (LfU, 2011). This is considered a satisfying result, given the small data pool for rare events of this kind when considering 30yr periods. For high flow extremes, the discharge for flood events occurring statistically every 10,50 and $100 \mathrm{yr}$ was analysed. The validation was inconclusive and presently considerable doubts remain as to the ability of the model chain realisations to simulate these measures for the future. Therefore, for the analysis of results for future time periods regarding high-flow and flood risk, only the mean monthly high flow (MoMHQ) is considered.

\subsection{Scenarios for adaptation}

The full realisation of 10 model chains (Table 1), from global climate model to impact model, produced a wide range of results for the Inn River basin. Some scenarios showed significant changes towards more flood prone conditions in winter months, whilst other scenarios showed developments towards more severe low-flow conditions. As each model chain realisation can be considered plausible, it can be concluded that each realisation contains adaptation relevant information.

In the context of a growing number of available climate projections spanning a wide range of possible future developments, this raises the question of how to proceed in future studies focusing on adaptation to climate change at the regional level. An important challenge is the identification of objective criteria for the selection of subsets of the available projections to serve as scenarios for adaptation. Identifying and testing possible objective criteria remains an ongoing process which is highly dependent on local and regional characteristics as well as the specific question at hand. A helpful intermediate step is the closer analysis of characteristic projections, for example those representing opposite - but not extreme - ends of the simulated spectrum. This is demonstrated on the basis of two hydrological projections: one "drought-prone" model chain realisation (WET10_eh), and one "high-flow increase scenario" (REM_UBA_b). It is worth noting that both hydrological scenarios have identical model chain beginnings up to the GCM. The global model run ECHAM5 r1(A1B), in combination with the statistical regional climate model WETTREG 2010 on the one hand and the dynamic climate model REMO on the other, produces significantly different results regarding temperature and precipitation. This is an indication of the enormous variability amongst different regional climate modelling methods and models.

Figure 4 shows the development of the climate change signal for the climatic variables temperature and precipitation for all the regional climate models listed in Table 1. Though all projections are characterised by temperature increases both in the summer and winter season, the temperature increase simulated by WET10_eh (Fig. 4, dashed black line) is stronger than the increase shown by REM_UBA_b for the first half of the 21st century. REM_UBA_b even shows a slight decrease at the beginning of the 21st century (Fig. 4, thick black line) but ends the century as one of the warmest projections, with an increase of more than $3.5^{\circ} \mathrm{C}$ for both the summer and winter season. WET10_eh is characterised by decreasing precipitation amounts in both summer and winter, setting it apart from most of the other projections that show increases in winter and decreases in summer. REM_UBA_b shows strong increases at the beginning of the century in winter, after which the level remains more or less constant, at about $+10-+15 \%$ above the levels of the reference period 1971-2000. In the summer months, REM_UBA_b, like many other projections, shows more or less unchanged conditions until the middle of the century after which the precipitation amounts decrease rapidly.

\section{3 "Drought-prone scenario"}

If only the near future (2021-2050) and the model chain realisations based on bias corrected dynamical regional climate models are considered, the results regarding frequent lowflow events, characterised by the measure MoMNQ, suggest that low-flow conditions will not become more severe in future (Table 2). However, there are several arguments against this assumption: firstly, only a limited number of regional climate models are included in this study and we cannot be sure the whole range has been covered, especially as the uniform application of bias correction methods to the dynamic RCM output may also have reduced the range of our results. Secondly, based on the validation results, each model chain realisation can be considered equally plausible and the results based on statistical downscaling approaches agree on a tendency towards decreases, even in the near future. Thirdly, the results for the distant future (2071-2100) show a high level of agreement on decreasing MoMNQ discharges (Table 2). This is explained at least in part by an overall reduction in 
Table 2. Changes [\%] in mean monthly low flow (MoMNQ) at gauge Passau-Ingling/Inn, in near and distant future (GLOWA projections not available for distant future), data relative to reference run of the respective climate projections in 1971-2000 for December-January-February (DJF), March-April-May (MAM) and June-July-August (JJA) September-October-November (SON) and averaged for the year.

\begin{tabular}{|c|c|c|c|c|c|c|c|c|c|c|}
\hline \multirow{2}{*}{$\begin{array}{l}\text { Change MoMNQ [\%] } \\
\text { Climate projection }\end{array}$} & \multicolumn{5}{|c|}{ 2021-2050 } & \multicolumn{5}{|c|}{$2071-2100$} \\
\hline & DJF & MAM & JJA & SON & Year & DJF & MAM & JJA & SON & Year \\
\hline REM_uba_b & 18 & 7 & -2 & 13 & 6 & 24 & -4 & -49 & -33 & -24 \\
\hline REM_bfg_b & 15 & 6 & 4 & 0 & 5 & 21 & -7 & -48 & -30 & -24 \\
\hline REM_ens_b & 7 & -5 & -7 & 6 & -2 & 31 & 1 & -39 & -20 & -15 \\
\hline CLM_hd_b & 17 & 10 & -6 & 11 & 5 & 19 & 3 & -42 & -25 & -18 \\
\hline CLM_eh_b & 10 & 6 & -6 & 5 & 2 & 20 & 6 & -48 & -32 & -21 \\
\hline CLM_eh2_b & 14 & 4 & -6 & -5 & 0 & 22 & -6 & -52 & -33 & -26 \\
\hline WET10_eh & 1 & -8 & -16 & -7 & -9 & -13 & -25 & -54 & -42 & -38 \\
\hline WET09_hd & -6 & -6 & -21 & -14 & -13 & -13 & -15 & -51 & -40 & -34 \\
\hline GLO_frt & 18 & 2 & -25 & -11 & -9 & & & & & \\
\hline GLO_rem & 21 & 11 & -22 & -6 & -4 & & & & & \\
\hline
\end{tabular}

White $=$ change less than $\pm 20 \%$; light grey $=$ decrease more than $20 \%$; dark grey $=$ increase more than $20 \%$.

Table 3. Same as Table 2 for mean monthly high flow (MoMHQ).

\begin{tabular}{|c|c|c|c|c|c|c|c|c|c|c|}
\hline \multirow{2}{*}{$\begin{array}{l}\text { Change MoMHQ [\%] } \\
\text { Climate projection }\end{array}$} & \multicolumn{5}{|c|}{$2021-2050$} & \multicolumn{5}{|c|}{$2071-2100$} \\
\hline & DJF & MAM & JJA & $\mathrm{SON}$ & Year & DJF & MAM & JJA & SON & Year \\
\hline REM_uba_b & 27 & 10 & 4 & 27 & 13 & 54 & 1 & -23 & -16 & -5 \\
\hline REM_bfg_b & 31 & 0 & 12 & 13 & 12 & 26 & -9 & -20 & -10 & -9 \\
\hline REM_ens_b & 14 & -10 & -10 & 29 & 2 & 43 & 2 & -15 & 26 & 6 \\
\hline CLM_hd_b & 27 & 13 & -6 & 1 & 5 & 29 & 8 & -21 & -7 & -4 \\
\hline CLM_eh_b & 7 & 13 & -1 & 10 & 6 & 37 & 17 & -30 & -23 & -7 \\
\hline CLM_eh2_b & 25 & -3 & 7 & 4 & 6 & 8 & 6 & -27 & -19 & -12 \\
\hline WET10_eh & -3 & -8 & -29 & -5 & -15 & -27 & -28 & -49 & -29 & -37 \\
\hline WET09_hd & -16 & -10 & -33 & -30 & -24 & -24 & -24 & -49 & -45 & -39 \\
\hline GLO_frt & 38 & 6 & -8 & -5 & 2 & & & & & \\
\hline GLO_rem & 30 & 14 & -26 & 1 & -3 & & & & & \\
\hline
\end{tabular}

White $=$ change less than $\pm 20 \%$; light grey $=$ decrease more than $20 \%$; dark grey $=$ increase more than $20 \%$.

precipitation. It appears likely that hydrological processes such as changes in snow cover also contribute to this effect, though this could not be proven within the scope of this study.

In view of these results and the remaining uncertainties, a precautionary approach would mean choosing a "droughtprone" hydrological scenario as a basis for any vulnerability assessment and consequent adaptation measures regarding low flow and drought. The aforementioned model chain realisation WET10_eh is a "dry" but still entirely plausible scenario (though, as mentioned in Sect. 3.3 WETTREG is generally considered less reliable for the distant future than for the near future).

Based on this hydrological projection, MoMNQ could decrease in the order of $-10 \%$ in the near future (2021-2050 compared with 1971-2000, decrease of $-16 \%$ in the summer months JJA and a decrease of $-9 \%$ averaged over the year). For the distant future, decreases in the order of $-40 \%$ are projected (2071-2100 compared with 1971-2000, decrease of $-54 \%$ in the summer months JJA and a decrease of $-38 \%$ averaged over the year). The monthly mean low flow at the Inn River basin exit gauge Passau-Ingling, as calculated based on measured discharge in the 20th century, lies in the order of $800 \mathrm{~m}^{3} \mathrm{~s}^{-1}$ for summer and $400 \mathrm{~m}^{3} \mathrm{~s}^{-1}$ for winter (Fig. 2). A reduction in summer by more than $-50 \%$, as estimated by this "drought-prone scenario" for the summer months in the distant future, would significantly change the summer runoff situation. Monthly low-flow means similar to those observed in the winter in the 20th century would also be possible in summer.

The results presented so far relate to the average lowflow measure MoMNQ. To analyse whether extreme lowflow events could become more severe in future, extreme value analysis assessing the frequency of the occurrence of such events was performed on the simulated discharge series for the near and distant future for the 13 gauges in the Inn River basin (background information on low flow analysis can be found in the WMO "Manual on Low-flow Estimation 

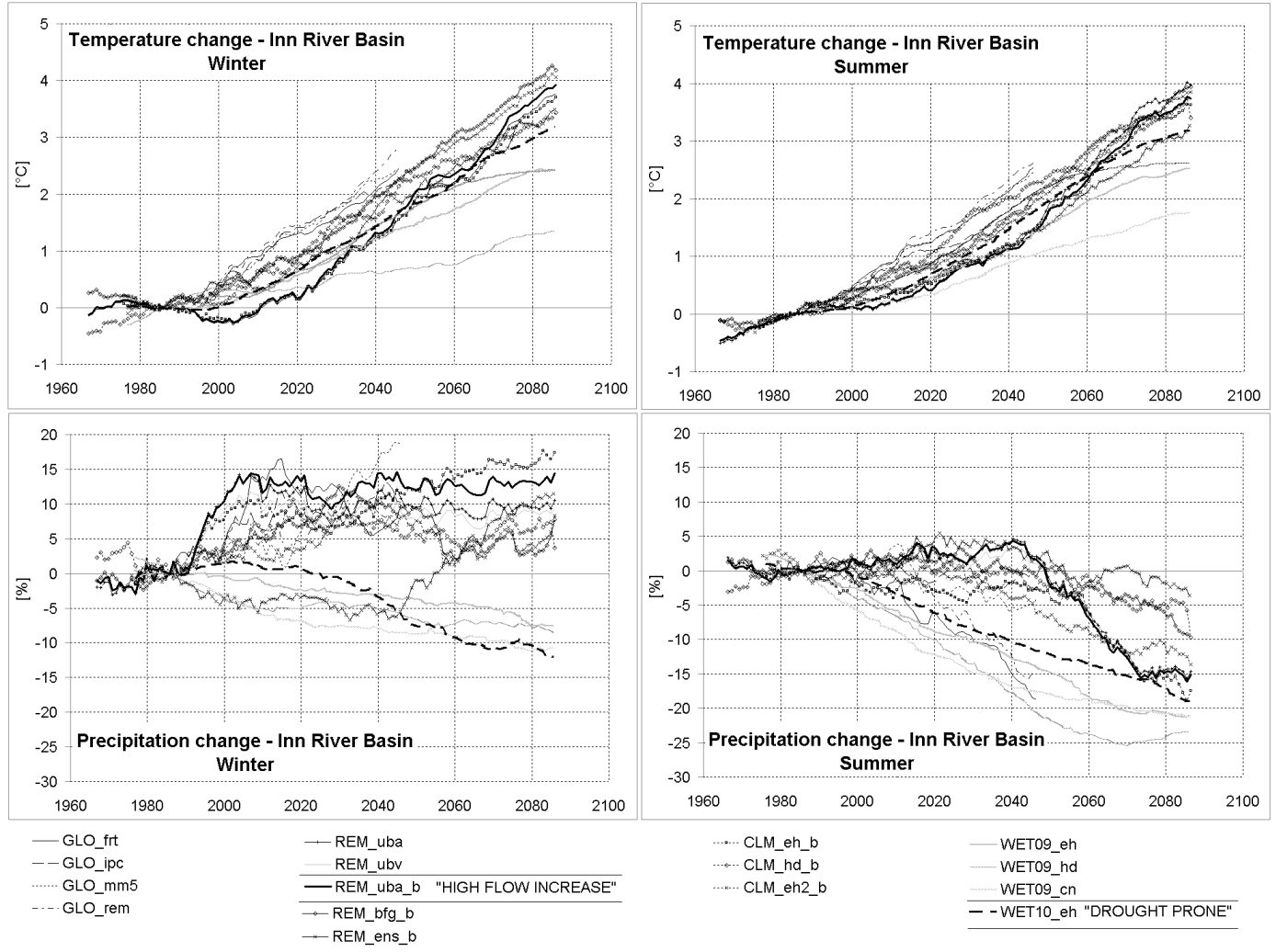

Fig. 4. Projected changes in temperature and precipitation in the Inn River basin; 30-yr-moving average vs. average for reference period (1971-2000) for hydrological winter season (November-April) and summer season (May-October); dashed black line: "drought-prone scenario" (WET10_eh), thick black line: "high-flow increase scenario" (REM_UBA_b).

and Prediction" by Tallaksen and Hewa, 2009). The results show that rare extreme low-flow events could become more severe, with decreases in the order of $-20 \%$ for low-flow discharge events occurring statistically every $50 \mathrm{yr}$ (NQ50) shown by WET10_eh for the period 2071-2100 compared with 1971-2000.

\section{4 "High-flow increase scenario"}

As described above, the results of climate change impact modelling for the measure "mean monthly high flow" (MoMHQ) were considered sufficiently reliable for the derivation of adaptation relevant information. Simulation results for extreme flood occurrence, e.g. climate induced changes in the 100-yr flood, could not be used with confidence. In this study, this makes MoMHQ the only measure that can be analysed with regard to potential changes in floods. These results only have very limited relevance to the question of changes in extreme flood occurrence, as they only provide an indication of the possible direction and order of magnitude of changes in frequently occurring high-flow conditions.

The model chain realisation REM_UBA_b, which has been shown to be plausible whilst at the same time representing the "high-flow increase" end of the analysed spectrum, showed increases in MoMHQ in the order of $+30 \%$ for autumn and winter months $(+27 \%$ for SON and DJF) for the near future (2021-2050 compared with 1971-2000) (Table 3). For the distant future (2071-2100 compared with 1971-2000) a decrease in MoMHQ is projected for autumn (SON $-16 \%)$ but at the same time the projected increase in winter reaches a value in the order of $+50 \%(+54 \%$ DJF). The projected changes can be attributed to the higher precipitation amounts in winter in combination with increasing temperatures leading to less snow and earlier flood peaks within the hydrological year.

\section{Summary and conclusions}

The different climate impact model chains produced a wide range of results for the Inn River basin, with some scenarios showing significant changes towards increasing highflow in winter months, whilst other scenarios showed developments towards more severe low-flow conditions, especially towards the end of the 21 st century. The validation of the results showed a satisfactory reproduction of the measured mean monthly runoff (MoMQ), mean monthly high 
flow (MoMHQ), mean monthly low flow (MoMNQ) as well as NQ50. Therefore, each model chain realisation can be considered plausible for these measures and it can be concluded that despite apparent contradictions, each realisation contains adaptation relevant information. This was demonstrated on the basis of two hydrological projections, one "drought-prone scenario" and one "high-flow increase scenario". These projections represent opposite ends of the simulated spectrum without taking on extreme values compared with the rest of the ensemble.

The "drought-prone scenario" showed a decrease in extreme low-flow discharge occurring statistically every $50 \mathrm{yr}$ (NQ50) in the order of $-20 \%$ and a decrease in mean monthly low flow (MoMNQ) in the order of $-40 \%$ towards the end of the 21 st century. The "high-flow increase scenario" produced significantly different results regarding climate induced changes in discharge, with projected increases in winter for MoMHQ in the order of $+30 \%$ for the near future and $+50 \%$ for the distant future.

The regional climate models showed weaknesses in reproducing observed statistics for extreme precipitation events in the 20th century and the validation results for the model chain regarding flood events with return periods of 10,50 and $100 \mathrm{yr}$ were not satisfactory. Consequently, only results for MoMHQ are available for the derivation of adaptation measures regarding high-flow and flooding. Until this situation improves, a precautionary approach within acceptable margins is recommended. A "good-practice-example" of this approach is the "climate-change-factor" used in Bavaria for the design value for flood protection measures (KLIWA, 2006). The design value is calculated by multiplying the discharge for the design event, usually the 100 -yr-flood, with a given factor (for the 100-yr-flood 1.15), thus deriving a design value that is, in this case, $15 \%$ higher than the respective statistical design event.

The findings presented here demonstrate the need to optimise the model chain in order to produce reliable projections, especially for flood events. In more general terms, the findings open up the possibility of optimising the model chain for different regions and different hydrological measures. This could include choosing a reference climate dataset that reproduces the relevant climatic measures particularly well, the strategic case-by-case selection of regional climate projections according to objective criteria based on the type of analyses shown here, and the calibration of the impact model with a special focus on model performance for the hydrological measures in question.

Acknowledgements. Observational data used in this work was provided by Zentralanstalt für Meteorologie und Geodynamik, Austria, Bundesamt für Meteorologie und Klimatologie, Switzerland, Deutscher Wetterdienst, Germany, Bayerisches Landesamt für Umwelt, Germany, Bundesamt für Umwelt, Switzerland, Bundesministerium für Land und Forstwirtschaft, Umwelt und Wasserwirtschaft, Austria, Kommission für Glaziologie, Germany,
Geodatenstelledes Landes Tirol, Austria, Schweizer Bundesamt für Statistik, Switzerland, European Environment Agency as well as Ludwig-Maximimilians-Universität, Munich, Germany, Institute for Atmospheric and Climate Science, Zurich, Switzerland and Geografisches Institut der Universität Bern, Switzerland. Some of the climate model data used in this work originate from the EU FP6 Integrated project ENSEMBLES (Contract number 505539) and from the research programme "klimazwei" of the German Federal Ministry of Education and Research. The bias-corrections were carried out by the Federal Institute of Hydrology, Germany: The support of all of the above is gratefully acknowledged. AdaptAlp was co-funded by the EU Alpine Space Programme. Part of this work was carried out within the research programme KLIWAS financed by the Federal Ministry of Transport, Building and Urban development and the cooperation project KLIWA financed by German federal states Bavaria, Baden-Württemberg and Rheinland-Pfalz and the German Weather Service.

Edited by: K. Schneider and S. Achleitner

Reviewed by: two anonymous referees

\section{References}

Auer, I., Böhm, R., Jurkovic, A., Lipa, W., Orlik, A., Potzmann, R., Schöner, W., Ungersböck, M., Matulla, C., Briffa, K., Jones, P. D., Efthymiadis, D., Brunetti, M., Nanni, T., Maugeri, M., Mercalli L., Mestre, O., Moisselin, J.-M., Begert, M., MüllerWestermeier, G., Kveton, V., Bochnicek, O., Stastny, P., Lapin, M., Szalai, S., Szentimrey T., Cegnar, T., Dolinar, M., GajicCapka, M., Zaninovic, K., Majstorovic, Z., and Nieplova, E.: HISTALP - Historical instrumental climatological surface time series of the greater Alpine region 1760-2003, Int. J. Climatol., 27, 17-46, 2007.

Bard, A., Renard, B., and Lang, M.: The AdaptAlp Dataset - Detecting climate-induced trends in observed river discharge data, AdaptAlp technical report, available at: www.adaptalp.org (last access: 17 October 2012), 2011.

Bayerisches Landesamt für Wasserwirtschaft: Hochwasser im August 2002 (mit Berichtigungen vom 28 October 2002), München, 2002.

Fowler, H. J., Blenkinsop, S., and Tebaldi, C.: Review - Linking climate change modelling techniques for hydrological modelling, Int. J. Climatol., 27, 1547-1578, 2007.

Gattermayr, W. and Steck, J.: Innsbruck und das Hochwasser, Geschichte und Geschichten geschrieben vom Inn, Abteilung Wasserwirtschaft der Tiroler Landesregierung, Innsbruck, Austria, 2006.

GLOWA Danube Projekt: Global Change Atlas. Einzugsgebiet Obere Donau, 5. Lieferung, available at: www.glowa-danube.de (last access: 17 October 2012), 2010.

Graham, L. P., Andreasson, J., and Carlsson, B.: Assessing climate change impacts on hydrology from an ensemble of regional climate models, model scales and linking methods - a case study on the Lule River basin, Climatic Change, 81, 293-307, 2007.

Hollweg, H.-D., Böhm, U., Fast, I., Hennemuth, B., Keuler, K., Keup-Thiel, E., Lautenschlager, M., Legutke, S., Radtke, K., Rockel, B., Schubert, M., Will, A., Woldt, M., and Wunram, C.: Ensemble Simulations over Europe with the Regional Climate Model CLM forced with IPCC AR4 Global Scenarios, Technical 
Report No. 3, Modelle \& Daten, Max-Planck Institut für Meteorologie, Hamburg, 150 pp., ISSN 1619-2257, 2008.

Jacob, D.: REMO climate of the 20th century run and A1B scenario run, UBA project, 0.088 degree resolution, $1 \mathrm{~h}$ data, World Data Center for Climate, CERA-DB, 2006.

Jacob, D., Nilson, E., Tomassini, L., and Bülow, K.: REMO climate of the 20th century run and A1B scenario run, BfG project, 0.088 degree resolution, $1 \mathrm{~h}$ data, World Data Center for Climate, CERA-DB, 2009.

Keuler, K., Lautenschlager, M., Wunram, C., Keup-Thiel, E., Schubert, M., Will, A., Rockel, B., and Boehm, U.: Climate Simulation with CLM, Climate of the 20th Century run No. 2, Data Stream 2: European region MPI-M/MaD, World Data Center for Climate, 2009a.

Keuler, K., Lautenschlager, M., Wunram, C., Keup-Thiel, E., Schubert, M., Will, A., Rockel, B., and Boehm, U.: Climate Simulation with CLM, Scenario A1B run No. 1, Data Stream 2: European region MPI-M/MaD, World Data Center for Climate, 2009b.

Keuler, K., Lautenschlager, M., Wunram, C., Keup-Thiel, E., Schubert, M., Will, A., Rockel, B., and Boehm, U.: Climate Simulation with CLM, Scenario A1B run No. 2, Data Stream 2: European region MPI-M/MaD, World Data Center for Climate, 2009c.

KLIWA: Langzeitverhalten der Hochwasserabflüsse in BadenWürttemberg und Bayern, Landesamt für Umwelt, Messungen und Naturschutz Baden-Württemberg, Karlsruhe, Germany, Bayerisches Landesamt für Umwelt, Augsburg, Germany, Deutscher Wetterdienst, Offenbach, Germany, KLIWA-Berichte 2, 2002.

KLIWA: Regionale Klimaszenarien für Süddeutschland - Abschätzung der Auswirkungen auf den Wasserhaushalt, Landesamt für Umwelt, Messungen und Naturschutz BadenWürttemberg, Karlsruhe, Germany, Bayerisches Landesamt für Umwelt, Augsburg, Germany, Deutscher Wetterdienst, Offenbach, Germany, KLIWA-Berichte 9, 2006.

Krahe, P., Nilson, E., Carambia, M., Maurer, T., Tomassini, L., Bölow, K., Jacob, D., and Moser, H.: Wirkungsabschätzung von Unsicherheiten der Klimamodellierung in Abflussprojektionen Auswertung eines Multimodell-Ensembles im Rheingebiet, Hydrol. Wasserbewirts., 53, 316-331, 2009.

Krahe, P., Carambia, M., Klein, B., Rachimow, C., Horsten, T., Nilson, E., Schikowski, G., Kling, H., Paulin, M., and Fuchs, M.: Präprozessierung und Anwendung von regionalen Klimaprojektionen für hydrologische Impaktstudien im Alpenraum, BfGBericht 1750, in preparation, 2012.

Lautenschlager, M., Keuler, K., Wunram, C., Keup-Thiel, E., Schubert, M., Will, A., Rockel, B., and Boehm, U.: Climate Simulation with CLM, Climate of the 20th Century run No. 1, Data Stream 2: European region MPI-M/MaD, World Data Center for Climate, 2009.

LfU (Bayerisches Landesamt für Umwelt): Gewässerkundlicher Bericht Hochwasser August 2005, Augsburg, 2007.

LfU (Bayerisches Landesamt für Umwelt): Water Balance Modelling for the Inn River, AdaptAlp technical report based on a report by: Pöhler, H., Wendel, S., Schultze, B., Karl, S., and Scherzer, J., available at: www.adaptalp.org (last access: 8 November 2011), 2010.
LfU (Bayerisches Landesamt für Umwelt): Klimawandel und Wasserhaushalt: Untersuchung zum Einfluss des Klimawandels auf Wasserbilanzen und Abflüsse für das Inneinzugsgebiet mittels verschiedener Klimaszenarien, AdaptAlp technical report based on a report by Willems, W. and Stricker, K., www.adaptalp. org (last access: 8 November 2011), 2011.

Mudelsee, M., Chirila, D., Deutschländer, T., Döring, C., Haerter, J., Hagemann, S., Hoffmann, H., Jacob, D., Krahe, P., Lohmann, G., Moeley, C., Nilson, E., Panferov, O., Rath, T., and Tinz, B.: Climate Model Bias Correction und die Deutsche Anpassungsstrategie, Mitteilungen Deutsche Meteorologische Gesellschaft, 3, 2 7, 2010.

Nakicenovic, N., Alcamo, J., Davis, G., de Vries, B., Fenhann, J., Gaffin, S., Gregory, K., Grübler, A., Jung, T. Y., Kram, T., La Rovere, E. L., Michaelis, L., Mori, S., Morita, T., Pepper, W., Pitcher, H., Price, L., Raihi, K., Roehrl, A., Rogner, H. H., Sankovski, A., Schlesinger, M., Shukla, P., Smith, S., Swart, R., van Rooijen, S., Victor, N., and Dadi, Z.: IPCC Special Report on Emissions Scenarios. Cambridge University Press, Cambridge, United Kingdom and New York, NY, USA, 2000.

Spekat, A., Enke, W., and Kreienkamp, F.: Neuentwicklung von regional hoch aufgelösten Wetterlagen für Deutschland und Bereitstellung regionaler Klimaszenarios auf der Basis von globalen Klimasimulationen mit dem Regionalisierungsmodell WETTREG auf der Basis von globalen Klimasimulationen mit ECHAM5/MPI-OM T63L31 2010 bis 2100 für die SRES Szenarios B1, A1B und A2, Umweltbundesamt (UBA), Germany, report, 2007.

Schulla, J.: Hydrologische Modellierung von Flussgebieten zur Abschätzung der Folgen von Klimaänderungen, Ph.D. thesis, Eidgenössische Technische Hochschule Zürich, Switzerland, 1997.

Schulla, J. and Jasper, K.: Modellbeschreibung WaSiM-ETH (Wasserhaushalts-Simulations-Modell ETH), Institut für Atmosphäre und Klima, ETH Zürich, Switzerland, technical report, 1998.

Schulla, J. and Jasper, K.: Model Description WaSiM-ETH, Zürich, Stallikon, Switzerland, 2007.

Tallaksen, L. M. and Hewa, G. A.: Extreme value analysis, in: Manual on Low-flow Estimation and Prediction, Operational Hydrology Report No. 50, WMO-No. 1029, 57-70, 2009.

UBA (Umweltbundesamt): Künftige Klimaänderungen in Deutschland - Regionale Projektionen für das 21. Jahrhundert, Hintergrundpapier, April 2006, updated in September 2006, Umweltbundesamt, Dessau-Rosslau, Germany, 2006.

Van der Linden, P. and Mitchell, J. F. B. (Eds.): ENSEMBLES: Climate Change and its Impacts: Summary of research and results from the ENSEMBLES project, Met Office Hadley Centre, Exeter, UK, 2009.

Weilguni, V.: Regionalisierung des Niederschlags, Wiener Mitteilungen, 197, 71-92, 2006. 